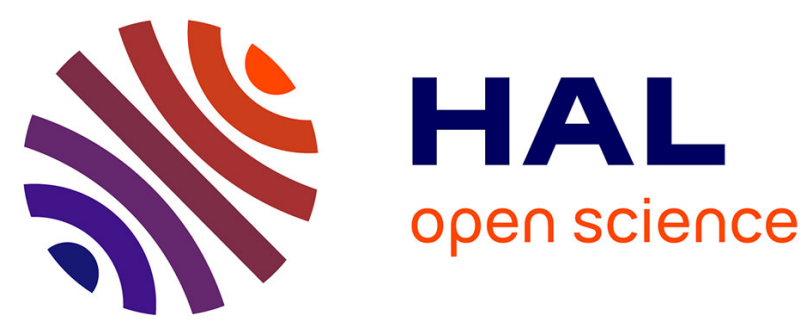

\title{
Old females rarely mate with old males in roe deer, Capreolus capreolus
}

Cécile Vanpé, Jean-Michel Gaillard, A. Hewison, Erwan Quéméré, Petter Kjellander, Maryline Pellerin, Jean-François Lemaître

\section{To cite this version:}

Cécile Vanpé, Jean-Michel Gaillard, A. Hewison, Erwan Quéméré, Petter Kjellander, et al.. Old females rarely mate with old males in roe deer, Capreolus capreolus. Biological Journal of the Linnean Society, 2019, 128 (3), pp.515-525. 10.1093/biolinnean/blz110 . hal-02390022

\section{HAL Id: hal-02390022 \\ https://hal.science/hal-02390022}

Submitted on 26 Jul 2021

HAL is a multi-disciplinary open access archive for the deposit and dissemination of scientific research documents, whether they are published or not. The documents may come from teaching and research institutions in France or abroad, or from public or private research centers.
L'archive ouverte pluridisciplinaire HAL, est destinée au dépôt et à la diffusion de documents scientifiques de niveau recherche, publiés ou non, émanant des établissements d'enseignement et de recherche français ou étrangers, des laboratoires publics ou privés. 


\title{
Old females rarely mate with old males in roe deer, Capreolus capreolus
}

\author{
CÉCILE VANPÉ ${ }^{1 * \dagger}$, JEAN-MICHEL GAILLARD ${ }^{1}$, A. J. MARK HEWISON ${ }^{2}$, \\ ERWAN QUEMERE ${ }^{2}$, PETTER KJELLANDER ${ }^{3}$, MARYLINE PELLERIN $^{4}$ and \\ JEAN-FRANÇOIS LEMAITTRE ${ }^{1}$
}

\author{
${ }^{1}$ Laboratoire de Biométrie et de Biologie Evolutive, Centre National de la Recherche Scientifique \\ UMR5558, Université Lyon 1, Villeurbanne, France \\ ${ }^{2}$ Comportement et Ecologie de la Faune Sauvage, Université de Toulouse, Institut National de la \\ Recherche Agronomique, Castanet Tolosan, France \\ ${ }^{3}$ Grimsö Wildlife Research Station, Department of Ecology, Swedish University of Agricultural Sciences, \\ Riddarhyttan, Sweden \\ ${ }^{4}$ Office National de la Chasse et de la Faune Sauvage, Direction de la Recherche et de l'Expertise - Unité \\ Ongulés Sauvages, Gières, France \\ ${ }^{\dagger}$ Current address: Office National de la Chasse et de la Faune Sauvage, Equipe Ours, Direction de la \\ Recherche et de l'Expertise - Unité Prédateurs et Animaux Déprédateurs, Impasse de la Chapelle, 31800 \\ Villeneuve de Rivière, France
}

\begin{abstract}
Little is known about whether female mating tactics vary with age based on their preference for mates. To fill this knowledge gap, we examined how maternal age is related to the age of their mates using detailed individual longterm monitoring of a genotyped and pedigreed European roe deer (Capreolus capreolus Linnaeus, 1758) population. We found that mating between old females and prime-aged males was more frequent than mating between primeaged females and prime-aged males. This suggests that old females avoid old mates. Old females might be more selective in their mate choice than prime-aged females owing to increased mate-sampling effort. Our finding is in line with the terminal investment/allocation hypothesis. The study of age-related variation in female mating behaviour is particularly important because this behaviour can influence the intensity and direction of sexual selection and the maintenance of variation in male sexually selected traits. Further studies are needed to quantify the exact fitness benefits of age-specific mating tactics in females.
\end{abstract}

ADDITIONAL KEYWORDS: age - cervid - mate choice - mating tactic - senescence - terminal allocation terminal investment.

\section{INTRODUCTION}

Age-specific variation is a general feature of most lifehistory traits in vertebrates (Emlen, 1970; Nussey et al., 2013; Gaillard et al., 2017). As a general rule, performance-related traits, such as reproduction or survival, initially increase with age during early life, reach a plateau during the prime-aged stage (i.e. between the age at first reproduction and the age at the onset of senescence) and decline with increasing

*Corresponding author. E-mail: cecile_vanpe@yahoo.fr age in response to senescence (Bouwhuis et al., 2012; Gaillard et al., 2017). In particular, with increasing availability of longitudinal monitoring of individuals from birth to death, empirical evidence of senescence in the wild is accumulating in both females and males (Nussey et al., 2013; Lemaître \& Gaillard, 2017).

However, so far, it remains unknown whether mating tactics vary with age in relationship to these changes in performance over the lifetime of an individual. The efficiency of female mating tactics (e.g. mate sampling, mate preference) might indeed track the general observed decline in physiological and reproductive 
performance (Berger et al., 2015; Froy et al., 2017). Alternatively, female mating tactics could be adjusted to buffer the deleterious effects of senescence (Lemaître \& Gaillard, 2017). Given that residual reproductive value decreases rapidly with increasing age, females should invest more in reproduction as they age (Williams, 1966), leading to the prediction of terminal allocation (sensu Weladji et al., 2010) or investment (Clutton-Brock, 1984). Previous attempts to test this hypothesis in various species have yielded contradictory results (Clutton-Brock, 1984; Descamps et al., 2007; Creighton et al., 2009; Weladji et al., 2010), although observations in mammalian females so far appear to be consistent overall with the predictions of terminal allocation/investment (Clutton-Brock, 1984; Ericsson et al., 2001).

Although most previous work has focused on agespecific changes in metrics of reproductive effort (Nussey et al., 2013; Lemaître \& Gaillard, 2017), agespecific reproductive tactics during the mating period may include increased preference for high-quality males as females age. The mating period can be very costly for females owing to the amount of time and energy that is required to search for and sample mates (e.g. Foley et al., 2018 in white-tailed deer, Odocoileus virginianus; Debeffe et al., 2014 in roe deer), in addition to the higher levels of predation risk, male aggression and inter-female aggressive behaviour (e.g. Byers et al., 2005 in female pronghorn, Antilocapra americana). Although a high level of choosiness might be associated with direct mortality costs, a change in mating tactics might potentially counterbalance the fitness costs of senescence (Lemaitre \& Gaillard, 2017). Nevertheless, evidence for increased female choosiness with female age in the wild, as predicted by the terminal allocation/investment hypothesis, remains scarce. This is probably because most theoretical and empirical studies of sexual selection have assumed that mating preferences are consistent over the reproductive lifespan of a female (Kokko et al., 2003). In fact, the few empirical studies in which age-specific variation in female mating preference has been observed have been conducted mostly in captive conditions and/or using laboratory-controlled experiments (e.g. Kodric-Brown \& Nicoletto, 2001 in fish; Richard et al., 2005 in reptiles; Mautz \& Sakaluk, 2008 in insects). Therefore, there is a clear need for empirical studies assaying age-specific variation in female mate preference in natural environments.

Male age is often considered to be a potential cue of male quality that can be used by females to maximize the direct and indirect benefits of mate choice (Hansen \& Price, 1995; Kokko \& Lindstrom, 1996). Although there is increasing empirical evidence for age-based female mate preference, it remains unclear whether females should prefer to mate with older males (Johnson \& Gemmell, 2012). In particular, some models predict that females should avoid mating with old males because they are likely to be of low genetic quality owing to the accumulation of deleterious germ-line mutations over time (Johnson \& Gemmell, 2012; Lemaître $\&$ Gaillard, 2017). In support of this hypothesis, female sandflies (Lutzomyia longipalpis) avoid mating with old males, possibly owing to the associated fitness cost (i.e. lower hatching rate; Jones et al., 2000). Clearly, we need more studies investigating how the age of both the male and the female partner affects female mate preference (Johnson \& Gemmell, 2012).

The European roe deer (Capreolus capreolus Linnaeus, 1758) is a small-sized cervid (adults weigh $\sim 20-30 \mathrm{~kg}$ ), with low sexual size dimorphism (males are $<10 \%$ heavier than females) and a weakly polygynous mating system (Vanpé et al., 2008). In this species, males are territorial during half of the year (including the rut), but females may also play an active role in mate choice (Liberg et al., 1998) by making short excursions outside their usual home range during the rut (San José \& Lovari, 1998; Lovari et al., 2008; Debeffe et al., 2014). Importantly, the probability of female excursion is not affected by age class (Debeffe et al., 2014). Furthermore, oestrous females frequently solicit courting from specific males and may reject copulation with non-territorial and/or young males (Danilkin \& Hewison, 1996), suggesting that female roe deer are choosy during mating.

We investigated age-specific variation in female mating tactics with respect to the age of their partner in an intensively monitored population of roe deer, for which a substantial proportion of individuals were genotyped and a multi-generational pedigree was constructed (see Quéméré et al., 2018). More specifically, we tested whether females showed evidence of terminal allocation in their mating tactics. Given that the individual performance of male roe deer typically declines with increasing age from 7-8 years of age onwards owing to senescence (e.g. male antler size, territorial status and breeding success: Vanpé et al., 2007, 2009a, c; survival: Gaillard et al., 1993, 2004; Loison et al., 1999), we expected old roe deer females to avoid mating with the oldest males. Given that studying female mate choice in the wild is difficult, especially in closed forest habitats, we used an indirect approach to test this hypothesis, examining how maternal age covaries with the age of their mates.

\section{MATERIAL AND METHODS}

\section{STUDY SITE AND POPULATION MONITORING}

The study was carried out in the Réserve Biologique Intégrale (RBI) of Chizé $\left(46^{\circ} 11^{\prime} \mathrm{N}, 0^{\circ} 34^{\prime} \mathrm{W}\right)$, a 2614 ha enclosed forest in western France, where habitat 
quality is rather poor and demographic performance low, especially in recent years (Gaillard et al., 2013). The roe deer population of Chizé has been monitored intensively for $>40$ years (since 1977), using winter annual capturemark-recapture sessions, in the context of a long-term ongoing project on roe deer ecology (Gaillard et al., 2013). Each winter, between six and 12 drive-netting capture sessions were carried out from October to March to capture juveniles (i.e. at $\sim 8$ months old) and adults (i.e. at $\geq 20$ months old). Newborns have also also caught by hand every spring (May_June) since 1985 (Gaillard et al., 1997). Each roe deer caught was sexed, aged (see details below), measured (e.g. body mass, antler size, hind-foot length), individually marked (with plastic coloured ear tags) and equipped with a numbered leather collar. Since 1996, some roe deer have been equipped with VHF or GPS collars. Ear punches $(\sim 2 \mathrm{~mm} \times 2 \mathrm{~mm})$ were collected for genetic analyses from all handled animals. All animals were then released on site. No roe deer hunting occurs in the RBI of Chizé. All capture, marking and handling procedures were carried out in accordance with French and European laws for animal welfare and approved by the University of Lyon (project DR2014-09) and the Director of Food, Agriculture and Forest (Prefectoral order 2009-14 from Paris).

\section{GENETIC ANALYSES AND PEDIGREE RECONSTRUCTION}

A total of 1941 roe deer were genotyped using 11 microsatellites (Vanpé et al., 2008; Quéméré et al., 2018). We constructed a multi-generational pedigree using parentage analyses based on genotypic data, life-history data (i.e. yearly capture rate, sex, birth year, first and last year of rut) and all known motheroffspring relationships, either from direct observation of newborns with their mothers or fawns at heel during the following autumn (Quéméré et al., 2018).

The maximum likelihood parentage-assignment method implemented in COLONY2 software (Jones \& Wang, 2010; Wang, 2012) allowed simultaneous genetic estimation of maternity, paternity, full sibships and paternal or maternal half-sibships, using a clustering method whereby individuals are placed into family groups with the highest likelihood (for full details, see Quéméré et al., 2018: supplementary text 1). We retained inferences with a level of confidence $>95 \%$ and which were fully congruent in at least three runs.

The pedigree contained 1696 individuals (born between 1996 and 2012), with 675 maternal links (48\%) and 645 paternal links (46\%) (from 360 different dams and 304 different sires). From this, we could infer which female conceived with which male. Overall, both parents were known for a total of 511 fawns. However, for each litter with full siblings $(N=51)$, we retained only one fawn, because we were interested in the mating event; therefore, our database finally included 460 mating events.

\section{INFERENCE OF AGE-SPECIFIC MATING PATTERN}

Parental age was defined as the age of the mother or father at fawn conception (i.e. during the rut). Age was either known based on tooth eruption (for individuals first caught as newborns or juveniles; Flerov, 1952; $N=454$ ) or estimated from tooth wear (for individuals $>1$ year of age; Hewison et al., 1999; $N=466$ ). Based on their known or estimated age, we categorized parents as either prime-aged (i.e. $\leq 7$ years old) or old (i.e. $\geq 8$ years of age). An age threshold of 7.5 years was used to distinguish between old and prime-aged animals because this corresponds to the onset of actuarial senescence in roe deer (Gaillard et al., 1993; Loison et al., 1999 on survival; Hewison \& Gaillard, 2001 on implantation success).

We considered all mating events where either both parents were of known age or one of the two parents was of known age and the other had an estimated age $(N=342)$. For the sake of accuracy, we did not include those mating pairs for which the age was estimated for both the mother and the father $(N=118)$, but note that results were very similar when they were included (for a summary of the results with the full dataset, $N=460$ mating events, see Supporting Information, Tables S1 and S2; Fig. S1). In addition, to minimize the risk of error in age-class attribution, we excluded mating pairs for which one or both of the parents had an estimated age of 7 or 8 years $(N=26)$, because the risk of misclassification of individuals was higher when the estimated age was close to the threshold of 7.5 years old. Our analyses were therefore performed on 316 mating events.

We attributed a 'quality index' for age estimation to each mating pair based on the degree of confidence we had when assigning individuals to either the 'prime-aged' or the 'old' group. More specifically, if the estimated age of either the mother or the father during the mating year was 5 or 6 years old, the parent that had an estimated age was classified as 'prime-aged', with a quality index for the mating pair of three (i.e. lowest quality). If the estimated age of either the mother or the father during the mating year was < 5 years old, the parent with an estimated age was classified as 'prime-aged', with a quality index for the mating pair of two (i.e. intermediate quality). In a similar manner, if the estimated age of either the mother or the father during the mating year was 9 or 10 years old, the parent with an estimated age was classified as 'old', with a quality index for the mating pair of three, whereas if the estimated age of either the mother or the father during the mating year was $>10$ years old, the parent with an estimated age was classified as 'old', with a quality index for the mating pair of two. Finally, we attributed a quality index for the mating pair of one (i.e. highest quality) to all parents 
of known age (i.e. first caught as newborn fawns or as 8-month-old fawns). The dataset (including a total of 316 mating events) is available in the Supporting Information (Table S3). Sample sizes for the different combinations of age-specific mating pairs (i.e. primeaged female-prime-aged male, old female-prime-aged male, prime-aged female-old male and old female-old male) in relationship to the age estimation quality index for the pair are provided in Table 1.

\section{STATISTICAL ANALYSES}

We analysed the age-specific variation in female mating tactics by studying the covariation between maternal age and the age of their mate. More specifically, we evaluated whether the probability that a female roe deer mated with a prime-aged male depended on its own age class, using generalized linear mixed-effect models with a binomial family and the glmer function implemented in the $\mathrm{R}$ lme4 package (Bates et al., 2015). The most general model included the additive effect of maternal age class (fitted as a two-modality factor: prime-aged vs. old) and age estimation quality index (fitted as a three-modality factor; see previous subsection) as fixed effects. In the most general model (maternal age class + quality index; see Supporting Information, Table S4), we therefore tested whether the probability that a female roe deer mated with a prime-aged male depended on its own age class and whether the 'quality index' for age estimation for each mating pair (i.e. the degree of confidence in age-class assignment) affected the results. We compared this model with the model including only the maternal age class effect (excluding the quality index effect) to test whether the probability that a female roe deer mated with a prime-aged male depended on its own age class irrespective of the quality index for the mating pair. These two models were compared with the constant model. Given that an individual female could feature several times in the dataset, both within (18 females featured more than once within a given year owing to multiple paternity) and among $(36,26$, three and one female featured two, three, four and five times among years, respectively) fawn cohorts, we included maternal identity and the fawn birth cohort as random effects to control for pseudo-replication issues.

Model selection was performed using the Akaike information criterion corrected for small sample size (AICc), as recommended by Burnham \& Anderson (2002). We retained the model with the lowest $\mathrm{AICc}$ value, reflecting the best compromise between precision and accuracy. The $\triangle \mathrm{AICc}$ is the difference in AICc between a given model and the model with the lowest AICc. When the $\triangle \mathrm{AICc}$ of two competing models was within two units, we retained the simplest model to satisfy parsimony rules. We also calculated AICc weights (wAICc) as a measure of the likelihood that a given model was the best among the set of fitted models. Given that the relevance and meaning of the $R^{2}$ metric have been criticized strongly by statisticians when applied to binomially distributed traits (see e.g. Cox \& Wermuth, 1992), we simply plotted the observed number of mating events in each age class against the predicted values. We also estimated the odds ratio for the probability that old females mated with a primeaged male vs. the probability that they mated with an old male as $p(1-q) / q(1-p)$, where $p$ is the probability that an old female mates with a prime-aged male and $q$ is the probability that a prime-aged female mates with a primeaged male. All statistical analyses were carried out using $R$ software (v.3.2.3; R Development Core Team, 2015).

\section{RESULTS}

When considering only individuals of known age $(N=98$ mating events), paternal age at conception ranged from 2 to 11 years old (mean $\pm \mathrm{SEM}=5.45 \pm 0.23$ years $)$, whereas maternal age at conception ranged from 1 to 12 years old (mean $\pm \mathrm{SEM}=4.36 \pm 0.28$ years; see Fig. $1 \mathrm{~A})$. We did not observe any mating events between old

Table 1. Sample sizes for the different combinations of age-specific mating pairs (i.e. prime-aged female-prime-aged male, old female-prime-aged male, prime-aged female-old male and old female-old male) in relationship to the age estimation quality index for the pair (either one, two or three, where one is the highest quality and three the lowest)

\begin{tabular}{|c|c|c|c|c|c|}
\hline \multirow[b]{2}{*}{ Maternal age class } & \multirow[b]{2}{*}{ Paternal age class } & \multicolumn{4}{|c|}{ Age estimation quality index } \\
\hline & & One & Two & Three & Total \\
\hline Prime-aged & Prime-aged & 64 & 107 & 51 & 222 \\
\hline Prime-aged & Old & 19 & 19 & 11 & 49 \\
\hline Old & Prime-aged & 15 & 20 & 7 & 42 \\
\hline Old & Old & 0 & 3 & 0 & 3 \\
\hline Total & & 98 & 149 & 69 & 316 \\
\hline
\end{tabular}

Note that maternal and paternal ages were defined as the age of the mother and the father, respectively, at fawn conception (i.e. during the rut). 
A

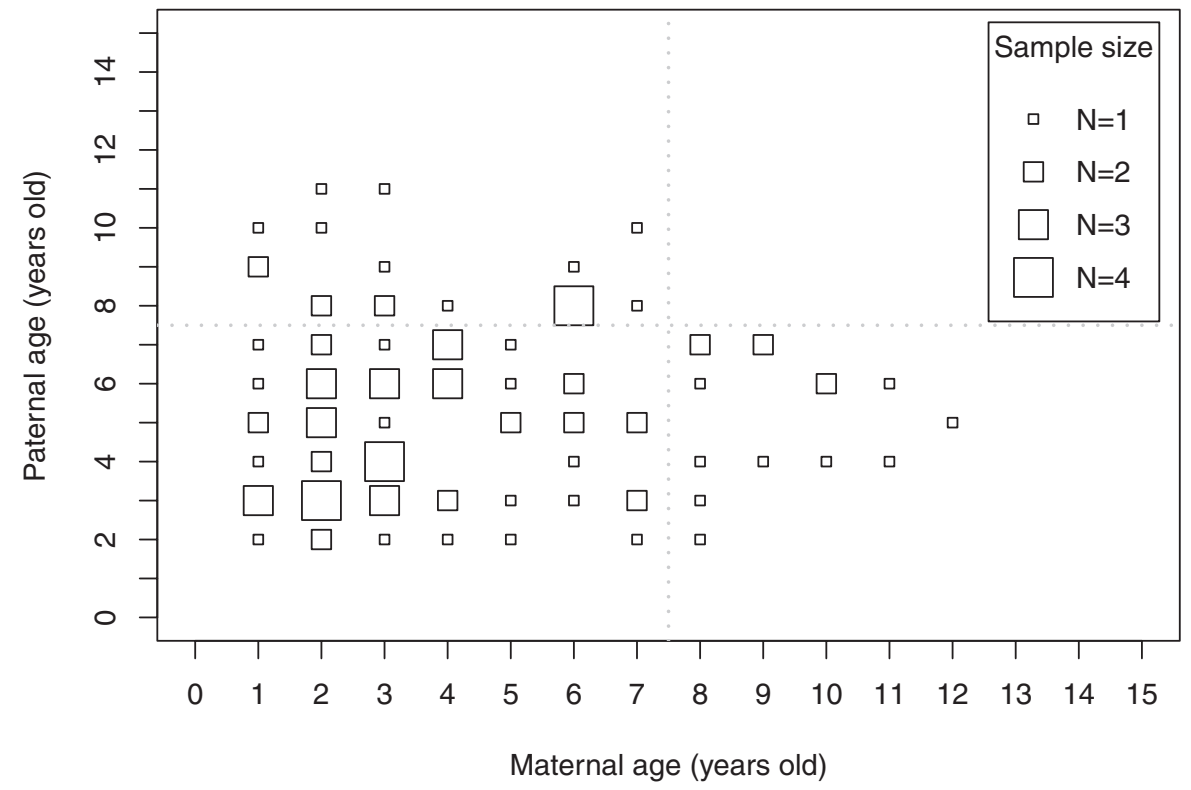

B

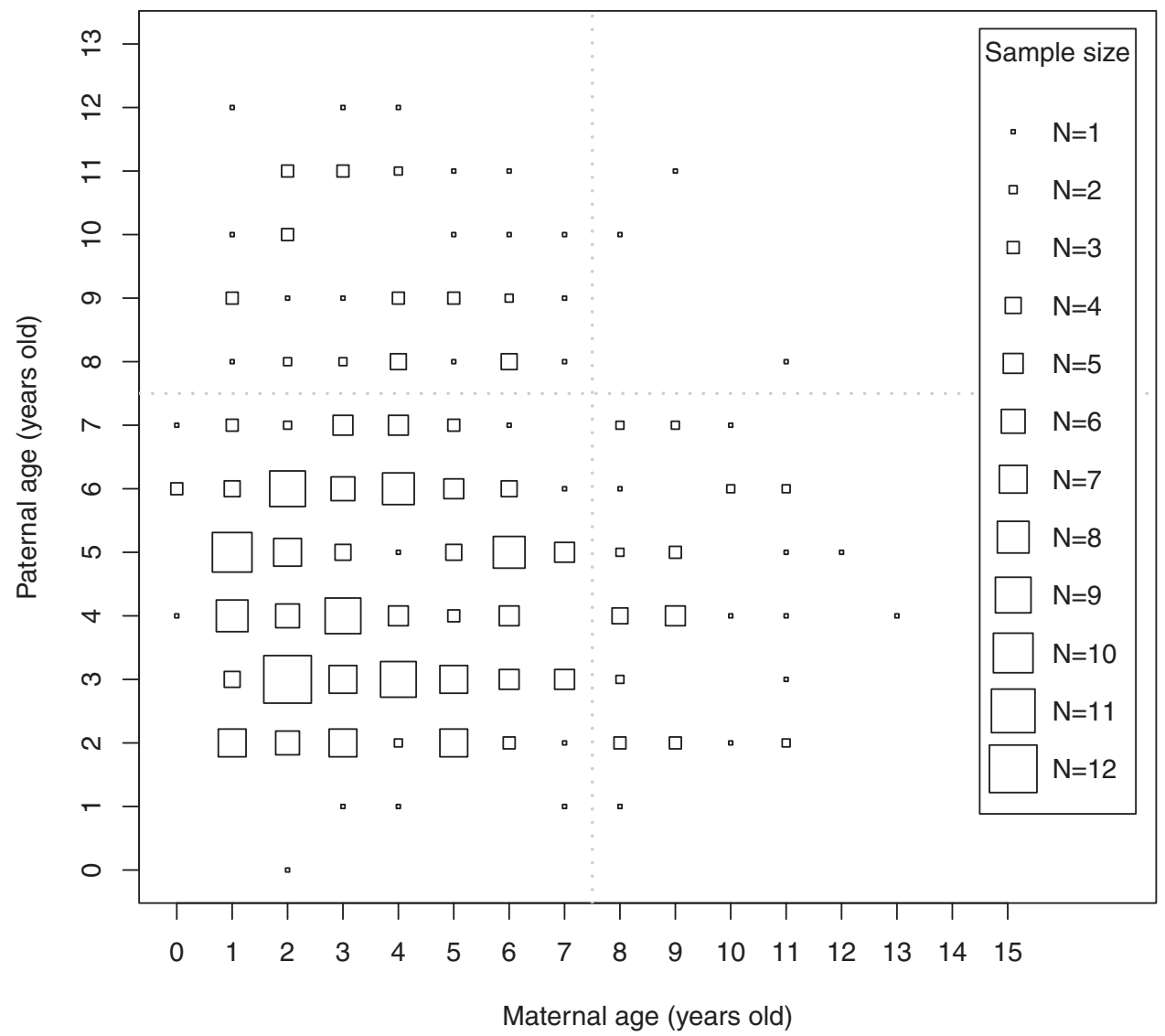

Figure 1. Relationship between paternal and maternal age (in years) in the European roe deer population of Chizé based on mating events between parents of known age only $(N=98 ; \mathrm{A})$ and based on all mating events in which at least one parent was of known age $(N=316 ; \mathrm{B})$. The size of each data point is proportional to sample size. The vertical and horizontal grey 
females and old males, although we expected between three and four mating events between old males and old females according to the population age structure (see Supporting Information, Table S5).

When analysing the full dataset, including all mating events where both parents were of known age or where one of the two parents was of known age and the other had an estimated age $(N=316$ mating events; see Fig. 1B), the selected model of variation in the probability that a female mated with a prime-aged male included the effect of maternal age class only ( $\triangle \mathrm{AICc}$ compared with the constant model $=-2.43 \mathrm{vs}$. -2.80 when including the additional effect of the age estimation quality index; see Supporting Information, Tables S4 and S6). The respective probabilities that an old female mated with either a prime-aged or an old male were 0.96 and 0.04 , and the respective probabilities that a prime-aged female mated with either a prime-aged or an old male were 0.87 and 0.13 . This generated an odds ratio of 3.59 for the comparison of the likelihood that an old female mated with a prime-aged male vs. an old male, indicating that, compared with prime-aged females, old females mated more frequently with prime-aged males than with old males. Indeed, only three of the 45 old females mated with an old male, whereas we expected between 11 and 12 mating events between old males and old females according to the population age structure (see Supporting Information, Table S5). The plot of the observed vs. predicted occurrences for the different combinations of age-specific mating events is provided in the Supporting Information (Fig. S2).

\section{DISCUSSION}

We found that mating events between old females and prime-aged males were much more frequent than mating events between prime-aged females and primeaged males in roe deer. A likely hypothesis to explain this pattern is that old females are more selective than prime-aged females in order to avoid mating with old males. Indeed, mating events between old females and old males were rarely observed in our dataset $(N=3$ out of 316 mating events with the dataset combining parents of known and estimated age, and $N=0$ out of 98 mating events when we restricted the dataset to parents of known age only). Importantly, this result is very unlikely to be influenced by the inter-annual variations in sex-age structure within the population. Indeed, except for one specific year (2005), the observed yearly probability of mating events between old females and old males in our population was always lower than the expected yearly probability of mating events between old females and old males under the assumption of random mating (for an analysis considering the yearly availabilities of prime-aged vs. old males and females in Chizé, see Supporting Information, Table S5).

The mating patterns we observed might result from direct or active mate choice, which implies that individuals are able to discriminate between mates and, as a consequence, mate preferentially with specific partners. It might also, alternatively or additionally, result from indirect or passive mate choice, which includes all other behaviours that limit the set of potential mates for a given individual, such as variation in the timing and/or location of mating events according to age class or dominance rank (see Farrell et al., 2011 on fallow deer Dama dama). The estimation of the pool of mates available to each female is particularly complex in roe deer, because a female can mate with one of the males whose territory overlaps with her home range or, alternatively, with an unknown and potentially large number of reproductive males that she may visit during rut excursions outside her 'normal' home range. In the RBI of Chizé (2614 ha enclosed), adult male territories have a mean diameter of 947 $\mathrm{m}(\mathrm{SD}=558 \mathrm{~m})$, and the mean distance of a rut excursion is $2.20 \mathrm{~km}(\mathrm{SD}=0.65 \mathrm{~km})$ (Debeffe et al,. 2014). As a consequence, females can potentially mate with a large proportion of males present in the population by making rut excursions, although they are more likely to mate with males that are in closer proximity. In contrast, roe deer males are generally faithful to their rutting territories for the whole of their reproductive lifespan (Hewison et al., 1998). In addition, male and female roe deer do not segregate (Bonenfant et al., 2007). Finally, no spatial or temporal segregation in mating events according to either dominance rank or age has been reported in this species thus far. Hence, there is no a priori reason to expect that the quality of males available for mating should differ between prime-aged and old females. Therefore, the most likely interpretation of our results is that direct mate choice drives the avoidance of old mates among old roe deer females.

dotted lines represent the threshold values for maternal and paternal age classes, respectively, fixed at 7.5 years. Maternal and paternal ages were defined as the age of the mother and the father, respectively, at fawn conception (i.e. during the rut). Note that in B, owing to uncertainty in age estimation, the age of some individuals was estimated to be 0 or 1 year. Mating events between old females and old males were rarely observed in our dataset $(N=0$ out of 98 mating events in A; $N=3$ out of 316 mating events in B). 
Two types of evidence are required to demonstrate that such non-random mating is a consequence of adaptive female mate choice. First, non-random mating should arise through female mate choice per se, rather than as a result of male-male competition or male mate choice (Halliday, 1983). In this regard, we know that female roe deer play an active role in the initiation of mating. Indeed, females frequently make short excursions outside their normal home range (see above). They mate with more than one male during a single reproductive season (Vanpé et al., 2009b). Finally, they frequently solicit courting from specific males and may refuse copulation with nonterritorial males (Danilkin \& Hewison, 1996; Liberg et al., 1998). In contrast, it is unlikely that old males mate selectively with younger females in roe deer. Indeed, territorial males have limited opportunity to sample females, because the territory of an individual male overlaps the home range of only a few females (Hewison et al., 1998; Liberg et al., 1998). Finally, territory boundaries are stable from one year to the next and, once territories have been settled on (in early spring), neighbouring males do not compete intensely for territories or mates ('always stay' and 'low risk-low gain' reproductive tactic; Vanpé et al., 2009c). Hence, the propensity of old females to mate more frequently with prime-aged males is likely to be a direct consequence of females becoming increasingly choosy with increasing age. Old roe deer females thus show evidence of terminal allocation in their mating tactics. Old females have a much lower residual reproductive value than prime-aged females owing to an age-related decline in female survival and recruitment that occurs from 7-8 years of age (Gaillard et al., 1993, 1998). Although the exact physiological and fitness costs of intensive mate searching remain to be assessed, our results suggest that old roe deer females might allocate more to reproductive behaviours than primeaged females (Lemaître \& Gaillard, 2017).

A second condition for female mate choice to be adaptive is that females that mate with preferred males should have higher fitness than females that mate at random (Halliday, 1983). Although there is increasing empirical evidence for age-based female mate preference (see review by Johnson \& Gemmell, 2012), its adaptive significance remains unclear. For instance, some models predict that females should prefer to mate with old males, because viability selection guarantees that they should be of high genetic quality, whereas others make the opposite prediction, that old males are likely to be of low genetic quality owing to the accumulation of deleterious germ-line mutations through time (Brooks \& Kemp, 2001; Johnson \& Gemmell, 2012). In roe deer, male reproductive senescence has been documented repeatedly and involves age-related declines in antler size, territorial status and breeding success (Vanpé et al., 2007, 2009a, c). This decline in reproductive performance at old age might potentially be linked to a decrease in male ejaculate quantity or quality (for a review, see Lemaître \& Gaillard, 2017), which has yet to be quantified in this species. In addition, offspring of old males might additionally suffer from mutations accumulated in the male germ-line (Pizzari et al., 2007). Therefore, old females might gain substantial fitness benefits by mating preferentially with younger and more fertile males. The expression of this mating preference might be particularly important for old females because they have lower reproductive success (Gaillard et al., 1998) and might aim to counterbalance this cost by mating with younger and potentially healthier males (Lemaître \& Gaillard, 2017). Note that although Debeffe et al. (2014) suggested that female rut excursion probability was not affected by age (i.e. yearling vs. adult), because they worked with animals of estimated age only they did not analyse whether this behaviour was consistent in later life. As a result, we currently do not have any reliable information on whether old females (i.e. > 7.5 years old) are more likely to perform rut excursions or whether they cover longer distances in order to sample more potential partners than prime-aged females (i.e. $<7.5$ years old).

A decrease in sperm production and sperm quality with increasing age has been documented in many species (Lemaître \& Gaillard, 2017). Given the assumption that a similar decline also occurs in roe deer bucks, a lower frequency of mating events between old females and old males compared with mating events between old females and prime-aged males is likely to be an indication of mate choice, with old females avoiding copulation with old males. However, in the present study, we used reproductive success as a proxy for mating success, because direct observations of mating in roe deer are extremely rare, especially in forest habitat, such as Chizé. Although roe deer females are monoestrous, they may mate with multiple males during a single oestrous period (Danilkin \& Hewison, 1996; Vanpé et al., 2009b). As a result, some of the males they mated with could go undetected in our dataset because of age-dependent post-copulatory sperm selection. In line with this possibility, the pattern we observed might result from lower sperm competitive abilities (e.g. lower concentration of sperm in the ejaculate) in old males. We did not have any behavioural and phenotypic data with which to test this prediction, but in Soay sheep (Ovis aries) the circumference of the testes declines with age, suggesting that old males might produce fewer sperm that younger males (Hayward et al., 2015).

Although some fawns included in the pedigree of the Chizé population were first captured as neonates 
within their first 3 weeks of life (Quéméré et al., 2018), most were caught for the first time at $\sim 8$ months old (i.e. first winter capture). Therefore, we cannot rule out the possibility that old female-old male pairings occur but that the embryos or fawns born from these mating events have extremely low survival owing to abortion or fawn mortality. The cumulative effect of male and female reproductive senescence in these mating pairs might thus be associated with high fitness costs (Lemaitre \& Gaillard, 2017). An important avenue of research is to determine whether the interaction between male and female age influences fawn survival. Further studies will be needed to quantify the exact fitness benefits of age-specific mating tactics for females and to evaluate the influence of this mating pattern on the strength of sexual selection. In particular, the next step is to compare how mate age influences juvenile survival, longevity, body condition and future reproductive success of the offspring in prime-aged and old females (e.g. Fay et al., 2016; Tidière et al., 2018).

\section{ACKNOWLEDGEMENTS}

We thank the numerous co-workers and volunteers for their assistance during roe deer captures, and Maxime Galan at Centre de Biologie pour la Gestion des Populations - Institut National de la Recherche Agronomique for genetic analyses. C.V. was funded by the 'AGEX' JCJC ANR project (ANR-15-CE32-0002-01) awarded to J.-F.L. The field study was supported by grants from ONCFS. Genetic data were produced thanks to the support of the 'PATCH' RPDOC ANR project (ANR-12-PDOC-0017-01) awarded to C.V. We are grateful to Luca Montana, Jason Airst and one anonymous referee for their helpful comments on a previous draft of this work.

\section{REFERENCES}

Bates D, Mächler M, Bolker B, Walker S. 2015. Fitting linear mixed-effects models using lme4. Journal of Statistical Software 67: 1-48.

Berger V, Lemaître J-F, Gaillard J-M, Cohas A. 2015. How do animals optimize the size-number trade-off when aging? Insights from reproductive senescence patterns in marmots. Ecology 96: 46-53.

Bonenfant C, Gaillard J-M, Dray S, Loison A, Royer M, Chessel D. 2007. Testing sexual segregation and aggregation: old ways are best. Ecology 88: 3202-3208.

Bouwhuis S, Choquet R, Sheldon BC, Verhulst S. 2012. The forms and fitness cost of senescence: age-specific recapture, survival, reproduction and reproductive value in a wild bird population. The American Naturalist 179: E15-E27.
Brooks R, Kemp DJ. 2001. Can older males deliver the good genes? Trends in Ecology \& Evolution 16: 308-313.

Burnham KP, Anderson DR. 2002. Model selection and multimodel inference: a practical information-theoretic approach. New York, USA: Springer-Verlag.

Byers JA, Wiseman PA, Jones L, Roffe TJ. 2005. A large cost of female mate sampling in pronghorn. The American Naturalist 166: 661-668.

Clutton-Brock TH. 1984. Reproductive effort and terminal investment in iteroparous animals. The American Naturalist 123: 212-229.

Cox DR, Wermuth N. 1992. A comment on the coefficient of determination for binary responses. Journal of the American Statistical Association 46: 1-4.

Creighton JC, Heflin ND, Belk MC. 2009. Cost of reproduction, resource quality, and terminal investment in a burying beetle. The American Naturalist 174: 673-684.

Danilkin AA, Hewison AJM. 1996. Behavioural ecology of Siberian and European roe deer. Chapman \& Hall: Springer Netherlands.

Debeffe L, Focardi S, Bonenfant C, Hewison AJM, Morellet N, Vanpé C, Heurich $M$, Kjellander $P$, Linnell JDC, Mysterud A, Pellerin M. 2014. A one night stand? Reproductive excursions of female roe deer as a breeding dispersal tactic. Oecologia 176: 431-443.

Descamps S, Boutin S, Berteaux D, Gaillard J-M. 2007. Female red squirrels fit Williams' hypothesis of increasing reproductive effort with increasing age. Journal of Animal Ecology 76: 1192-1201.

Emlen JM. 1970. Age specificity and ecological theory. Ecology 51: 588-601.

Ericsson G, Wallin K, Ball JP, Broberg M. 2001. Agerelated reproductive effort and senescence in free-ranging moose, Alces alces. Ecology 82: 1613-1620.

Farrell ME, Briefer E, McElligott AG. 2011. Assortative mating in fallow deer reduces the strength of sexual selection. PLoS One 6: e18533.

Fay R, Barbraud C, Delord K, Weimerskirch H. 2016. Paternal but not maternal age influences early-life performance of offspring in a long-lived seabird. Proceedings of the Royal Society B: Biological Sciences 283: 20152318.

Flerov KK. 1952. Fauna of the USSR: mammals. Vol. 1, no. 2. Musk deer and deer. Moscow: Academy of Sciences of the USSR.

Foley AM, Hewitt DG, DeYoung RW, Schnupp MJ, Hellickson MW, Lockwood MA. 2018. Reproductive effort and success of males in scramble-competition polygyny: Evidence for trade-offs between foraging and mate search. Journal of Animal Ecology 87: 1600-1614.

Froy H, Lewis S, Nussey DH, Wood AG, Phillips RA. 2017. Contrasting drivers of reproductive ageing in albatrosses. Journal of Animal Ecology 86: 1022-1032.

Gaillard J-M, Boutin JM, Delorme D, Van Laere G, Duncan $P$, Lebreton JD. 1997. Early survival in roe deer: causes and consequences of cohort variation in two contrasted populations. Oecologia 112: 502-513.

Gaillard J-M, Delorme D, Jean-Marie B, Van Laere G, Boisaubert B, Pradel R. 1993. Roe deer survival patterns: 
a comparative analysis of contrasting populations. Journal of Animal Ecology 62: 778-791.

Gaillard J-M, Garratt M, Lemaître J-F. 2017. Senescence in mammalian life-history traits. In: Shefferson RP, Jones OR, Salguero-Gomez R, eds. The evolution of senescence in the tree of life. Cambridge: Cambridge University Press, 126-155.

Gaillard J-M, Hewison AJM, Klein F, Plard F, Douhard M, Davison R, Bonenfant C. 2013. How does climate change influence demographic processes of widespread species? Lessons from the comparative analysis of contrasted populations of roe deer. Ecology Letters 16: 48-57.

Gaillard J-M, Liberg O, Andersen R, Hewison AJM, Cederlund G. 1998. Population dynamics of roe deer. In: Andersen R, Duncan P, Linnell JDC, eds. The European roe deer: the biology of success. Oslo: Scandinavian University Press, 309-335.

Gaillard J-M, Viallefont A, Loison A, Festa-Bianchet M. 2004. Assessing senescence patterns in populations of large mammals. Animal Biodiversity and Conservation 27: 47-58.

Halliday TR. 1983. The study of mate choice. In: Bateson P, ed. Mate choice. Cambridge: Cambridge University Press, 3-32.

Hansen TF, Price DK. 1995. Good genes and old age: do old mates provide superior genes? Journal of Evolutionary Biology 8: 759-778.

Hayward AD, Moorad J, Regan CE, Berenos C, Pilkington JG, Pemberton JM, Nussey DH. 2015. Asynchrony of senescence among phenotypic traits in a wild mammal population. Experimental Gerontology 71: 56-68.

Hewison AJM, Gaillard J-M. 2001. Phenotypic quality and senescence affect different components of reproductive output in roe deer. Journal of Animal Ecology 70: 600-608.

Hewison AJM, Vincen J-P, Angibault J-M, Delorme D, Van Laere G, Gaillard J-M. 1999. Tests of estimation of age from tooth wear on roe deer of known age: variation within and among populations. Canadian Journal of Zoology 77: 58-67.

Hewison AJM, Vincent J-P, Reby D. 1998. Social organisation of European roe deer. In: Andersen R, Duncan P, Linnell JDC, eds. The European roe deer: the biology of success. Oslo: Scandinavian University Press, 189-219.

Johnson SL, Gemmell NJ. 2012. Are old males still good males and can females tell the difference? Bioessays 34: 609-619.

Jones TM, Balmford A, Quinnell RJ. 2000. Adaptive female choice for middle-aged mates in a lekking sandfly. Proceedings of the Royal Society B: Biological Sciences 267: 681-686.

Jones OR, Wang J. 2010. COLONY: a program for parentage and sibship inference from multilocus genotype data. Molecular Ecology Resources 10: 551-555.

Kodric-Brown A, Nicoletto PF. 2001. Age and experience affect female choice in the guppy (Poecilia reticulata). The American Naturalist 157: 316-323.

Kokko H, Brooks R, Jennions MD, Morley J. 2003. The evolution of mate choice and mating biases. Proceedings of the Royal Society B: Biological Sciences 270: 653-664.
Kokko H, Lindstrom J. 1996. Evolution of female preference for old mates. Proceedings of the Royal Society B: Biological Sciences 263: 1533-1538.

Lemaître J-F, Gaillard J-M. 2017. Reproductive senescence: new perspectives in the wild. Biological Reviews 92: 2182-2199.

Liberg O, Johansson A, Anderssen R, Linnell JDC. 1998. Mating system, mating tactics and the function of male territoriality in roe deer. In: Andersen R, Duncan P, Linnell JDC, eds. The European roe deer: the biology of success. Oslo: Scandinavian University Press, 221-256.

Loison A, Festa-Bianchet M, Gaillard J-M, Jorgenson JT, Jullien J-M. 1999. Age-specific survival in five populations of ungulates: evidence of senescence. Ecology 80: 2539-2554.

Lovari S, Bartolommei P, Meschi F, Pezzo F. 2008. Going out to mate: excursion behaviour of female roe deer. Ethology 114: $886-896$.

Mautz BS, Sakaluk SK. 2008. The effects of age and previous mating experience on pre-and post-copulatory mate choice in female house crickets (Acheta domesticus L.). Journal of Insect Behavior 21: 203-212.

Nussey DH, Froy H, Lemaître J-F, Gaillard J-M, Austad SN. 2013. Senescence in natural populations of animals: widespread evidence and its implications for biogerontology. Ageing Research Reviews 12: 214-225.

Pizzari T, Cornwallis CK, Froman DP. 2007. Social competitiveness associated with rapid fluctuations in sperm quality in male fowl. Proceedings of the Royal Society B: Biological Sciences 274: 853-860.

Quéméré E, Gaillard J-M, Galan M, Vanpé C, David I, Pellerin M, Kjellander P, Hewison AJM, Pemberton JM. 2018. Between-population differences in the genetic and maternal components of body mass in roe deer. $B M C$ Evolutionary Biology 18: 39.

R Development Core Team. 2015. $R$ : a language and environment for statistical computing. Vienna: $\mathrm{R}$ Foundation for Statistical Computing. Available at: https://www.Rproject.org/

Richard M, Lecomte J, De Fraipont M, Clobert J. 2005. Age-specific mating strategies and reproductive senescence. Molecular Ecology 14: 3147-3155.

San José CS, Lovari S. 1998. Ranging movements of female roe deer: do home-loving does roam to mate? Ethology 104: 721-728.

Tidière M, Thévenot $\mathrm{X}$, Deligiannopoulou A, Douay G, Whipple M, Siberchicot A, Gaillard J-M, Lemaître J-F. 2018. Maternal reproductive senescence shapes the fitness consequences of the parental age difference in ruffed lemurs. Proceedings of the Royal Society B: Biological Sciences 285: 20181479.

Vanpé C, Gaillard J-M, Kjellander P, Mysterud A, Magnien P, Delorme D, Van Laere G, Klein F, Liberg O, Hewison AJM. 2007. Antler size provides an honest signal of male phenotypic quality in roe deer. The American Naturalist 169: 481-493.

Vanpé C, Gaillard J-M, Morellet N, Kjellander P, Liberg O, Delorme D, Hewison AJM. 2009a. Age-specific variation in male breeding success of a territorial ungulate 
species, the European roe deer. Journal of Mammalogy 90: 661-665.

Vanpé C, Kjellander P, Gaillard J-M, Cosson J-F, Galan M, Hewison AJM. 2009b. Multiple paternity occurs with low frequency in the territorial roe deer, Capreolus capreolus. Biological Journal of the Linnean Society 97: 128-139.

Vanpé C, Kjellander P, Galan M, Cosson J-F, Aulagnier S, Liberg O, Hewison AJM. 2008. Mating system, sexual dimorphism, and the opportunity for sexual selection in a territorial ungulate. Behavioral Ecology 19: 309-316.

Vanpé C, Morellet N, Kjellander P, Goulard M, Liberg O, Hewison AJM. 2009c. Access to mates in a territorial ungulate is determined by the size of a male's territory, but not by its habitat quality. Journal of Animal Ecology 78: $42-51$.

Wang J. 2012. Computationally efficient sibship and parentage assignment from multilocus marker data. Genetics 191: 183-194.

Weladji RB, Holand $\varnothing$, Gaillard J-M, Yoccoz NG, Mysterud A, Nieminen M, Stenseth NC. 2010. Agespecific changes in different components of reproductive output in female reindeer: terminal allocation or senescence? Oecologia 162: 261-271.

Williams GC. 1966. Natural selection, the costs of reproduction, and a refinement of Lack's principle. The American Naturalist 100: 687-690.

\section{SUPPORTING INFORMATION}

Table S1. Dataset including the 316 mating events used in the analyses. For each mating event, the fawn, mother and father identities (ID), fawn birth cohort, paternal and maternal age classes (fitted as a two-modality factor: prime-aged vs. old) and age estimation quality index (fitted as a three-modality factor: one vs. two vs. three) were provided. A quality index of one, two and three corresponds, respectively, to the highest, intermediate and lowest qualities (or confidence in age class assignation; see main text for further details).

Table S2. Model selection procedure for the generalized linear mixed-effect model (binomial family, with mother identity and birth cohort fitted as random effects) testing the effects of maternal age class (fitted as a twomodality factor: prime-aged vs. old) and age estimation quality index for the pair (fitted as an eight-modality factor; see below for further details) on the probability that a roe deer female mated with a prime-aged male, using all mating events between males and females of either known or estimated age $(N=460)$.

Table S3. Parameter estimates of the generalized linear mixed-effect model selected to describe the relationship between the probability that a roe deer female mated with a prime-aged male and maternal age class [fitted as a two-modality factor: prime-aged (PA) vs. old, with old maternal age class set as the reference category] as a fixed effect and with maternal identity and fawn birth cohort fitted as random effects, using all mating events between males and females of either known or estimated age $(N=460)$.

Table S4. Model selection procedure for the generalized linear mixed-effect model (binomial family, with maternal identity and birth cohort fitted as random effects) testing the effects of maternal age class (fitted as a two-modality factor: prime-aged vs. old) and age estimation quality index (fitted as a three-modality factor; see main text for further details) on the probability that a roe deer female mated with a prime-aged male, using all mating events where either both parents were of known age or one of the two parents was of known age and the age of the other was estimated $(N=316)$.

Table S5. Yearly proportions of the different age-sex classes (OF, old females; OM, old males; PAF, prime-aged females; PAM, prime-aged males), expected yearly mating probabilities for the different combinations of agespecific mating pairs under the assumption of random mating and considering the availability of the different age classes in males and females, and observed yearly mating probabilities for the different combinations of agespecific mating pairs based on the full dataset, including parents of either known age or estimated age $(N=460)$ in the roe deer population of Chizé and for the rut years between 1996 and 2008.

Table S6. Parameter estimates of the generalized linear mixed-effect model selected to describe the relationship between the probability that a roe deer female mated with a prime-aged male and maternal age class [fitted as a twomodality factor: prime-aged (PA) vs. old, with old maternal age class set as the reference category] as a fixed effect and with maternal identity and fawn birth cohort fitted as random effects, using all mating events where either both parents were of known age or where one of the two parents was of known age and the age of the other was estimated $(N=316)$. Figure S1. Relationship between paternal and maternal age (in years) in the European roe deer population of Chizé when including all mating events between males and females of either known or estimated age $(N=460)$. The size of each data point is proportional to the sample size. The vertical and horizontal grey continuous lines represent the threshold values for maternal and paternal age classes, respectively, fixed at 7.5 years. Maternal and paternal ages were respectively defined as the age of the mother and the father at fawn conception (i.e. during the rut).

Figure S2. Observed vs. predicted occurrences of the different combinations of age-specific mating pairs (i.e. prime-aged female-prime-aged male, old female-prime-aged male, prime-aged female-old male and old female-old 
male) for the selected generalized linear mixed-effect model (binomial family, with maternal identity and birth cohort fitted as random effects) describing the probability that a roe deer female mated with a prime-aged male as a function of the maternal age class (fitted as a two-modality factor: prime-aged vs. old) using all mating events where either both parents were of known age or one of the two parents was of known age and the age of the other was estimated $(N=316)$. 